\title{
Tracking of Resistant Salmonella Species in Poultry Farms: New Method of Control Using Essential Oils Nano-Emulsion Conjugated with Antimicrobial Agents
}

\author{
H. S. H. Salam ${ }^{a}$, A. N. Mohammed ${ }^{b}$, A. R. Hosni ${ }^{\mathrm{c}, *}$, \& A. A. E. Shehata ${ }^{\mathrm{d}}$ \\ aDepartment of Bacteriology, Mycology, and Immunology, Faculty of Veterinary Medicine, Beni-Suef University, \\ Beni-Suef 62511, Egypt \\ ${ }^{b}$ Department of Hygiene, Zoonoses, and Epidemiology, Faculty of Veterinary Medicine, Beni-Suef University, \\ Beni-Suef 62511, Egypt \\ 'Directorate of Veterinary Medicine, El-Fayoum, Egypt \\ ${ }^{d}$ Department of Bacteriology, Animal Health Research Institute, El-Fayoum Laboratory, El-Fayoum, Agricultural \\ Research Center, Egypt \\ *Corresponding author: amanyreda31@yahoo.com \\ (Received 24-02-2021; Revised 02-05-2021; Accepted 11-05-2021)
}

\begin{abstract}
This work was designed to monitor and track Salmonella spp. in the different internal organs (heart, liver, spleen, and caecum) of 247 bird species (chickens $n=176$, chicks $n=47$, ducks $n=15$, and ducklings $n=9$ ) with variable ages in two governorates; El-Fayoum and Beni-Suef, Egypt. Besides assessing the antimicrobial activity of antibacterial agents, essential oils, oils nano-emulsion, and their interactions with each other against salmonellae isolates for their control at the farm level. All samples were collected aseptically for further microbiological and serological investigations. Moreover, the efficiency of essential oils and oils nano-emulsion (thymol, carvacrol, basil, and cinnamon) against recovered Salmonellae were tested using the agar dilution method. A total of fourteen Salmonella serotypes were detected from different investigated internal organs (heart, liver, and spleen), and the three most predominant serovars were S. virchow (17.14\%), S. infantis (11.43\%), and S. anatum (11.43\%). The resistance profile of Salmonella spp. referred to $47.14 \%, 40.0 \%, 31.43 \%, 25.71 \%, 21.43 \%, 21.43 \%$, and $21.43 \%$ against ampicillin, chloramphenicol, gentamicin, aztreonam, cefazolin, cefotaxime, and tobramycin, respectively. The ability of essential oils (carvacrol oil $0.01 \%$, basil $0.1 \%$, cinnamon $0.01 \%$, and thymol oil $0.01 \%$ ) to inhibit the growth of Salmonellae differed significantly at $34.29 \%$, $17.14 \%, 11.43 \%$, and $1.43 \%$, respectively $(\mathrm{p}<0.05)$. Oppositely, essential oils nano-emulsion (thymol $0.01 \%$, carvacrol $0.001 \%$, basil $0.1 \%$, and cinnamon $0.01 \%$ ) showed no inhibitory effect on the growth of Salmonella species. In conclusion, the interactive action between essential oils and antimicrobial agents approved the ability to enhance the susceptibility of the resistant Salmonella isolates against gentamicin, tobramycin, chloramphenicol, and cefazolin. In addition, the interactive action between essential oils nano-emulsion and antimicrobial agents on resistant Salmonella isolates revealed a complete enhanced effect against cefotaxime and variable enhancement against aztreonam.
\end{abstract}

Keywords: Salmonella spp.; poultry farms; essential oils; multidrug resistance; nano-emulsion

\section{INTRODUCTION}

Nowadays, the poultry industry has a high economic implication and is considered an important source of animal protein. In addition, any diseases affecting poultry might cause death and subsequently may cause a drop in investment. Therefore, most of the poultry farms subjected to any bacterial, viral, and/or parasitic diseases must be treated, and so biosecurity and hygienic measures should be taken to ensure a successful production cycle in different farms (EFSA et al., 2019).

Different lesions in the internal organs of birds affected by Salmonella spp. were demonstrated (Hessen, 2006). Sometimes no lesions were found in acute deaths characterized by a septicemic picture in the internal organs.
Among different ages of birds, bacterial diseases could cause high complications in poultry farms. Moreover, the infection with Salmonella spp. among different ages of poultry compromises a severe drop in poultry production. Clinically, chicks affected by salmonellosis showed poor growth, weakness, ruffled feathers, closed eyes, droopy wings, weight loss, diarrhea, and dehydration. Furthermore, postmortem (P/M) lesions of salmonellosis are represented by the enlarged liver with necrosis and spleen, unabsorbed yolk sac, and enteritis with necrotic lesions in the mucosa (Hessen, 2006).

Salmonella infection causes significant economic losses in the poultry industry due to the costs of surveillance, investigation, treatment, and illness prevention (Shekhar, 2018). Furthermore, salmonellosis kills 
birds and has a negative impact on their performances (Mshelbwala et al., 2017)

Currently, there are 2600 Salmonella serotypes scattered worldwide (Guibourdenche et al., 2010). The different Salmonella serotypes commonly detected among poultry include Salmonella typhimurium, Salmonella enteritidis, Salmonella infantis, Salmonella montevideo, Salmonella newport, and Salmonella pullorum (Kumar et al., 2019). Moreover, S. typhimurium and S. enteritidis were recorded in the highest percentage among Specific-pathogen-free of poultry chickens besides $S$. Montevideo (Osman et al., 2010; Hendriksen et al., 2011). Ducks are potential reservoirs for Salmonella serovars, mainly S. enteritidis and S. anatum (Yang et al., 2019). On the other hand, mostly $S$. enteritidis and S. typhimurium had zoonotic importance as foodborne pathogens that cause food poisoning in humans (EFSA and ECDC, 2016).

Variable antimicrobial classes are used for the treatment of Salmonella serotypes in the veterinary field. Members of aminoglycosides usually have good antimicrobial effects on the treatment of Salmonellae (Hossain et al., 2015). The resistance pattern of Gram-negative bacteria to antibacterial agents is higher than that of the Gram-positive ones due to an additional outer membrane acting as an effective barrier for amphipathic agents (Cole et al., 2014; Elshafie et al., 2016). To overwhelm the resistance patterns of Salmonellae and the bad effect of withdrawal time of antibiotics, using natural herbs including some essential oils (Thymol, carvacrol, basil, and cinnamon), which have strong inhibitory effects on Salmonella serovars (Rattanachaikunsopon \& Phumkhachorn, 2010; Sakkas \& Papadopoulou, 2017) is recommended. Furthermore, the preparation of oil in nano-emulsion will potentiate the inhibitory effect of the low-size particles that facilitate the application of essential oils (Chouhan et al., 2017; Pathania et al., 2018). The current study was designed to determine the prevalence rate of Salmonella spp. in different poultry farms, assess the antimicrobial activity of antibacterial agents, some essential oils, and oils nano-emulsion. In addition, this study was also designed to evaluate the use and exploitation of essential oils and/or oil nano-emulsion in the presence of antimicrobial agents for enhancing their effectiveness to control Salmonella serotypes in the birds and their environments.

\section{MATERIALS AND METHODS}

\section{Ethical Approval}

According to the animal ethics guidelines, this current study was approved by Institutional Animal Care and Use Committee (IACUC) with reference No. 021-156.

\section{Study Area and Period}

This study was conducted on different birds in variable poultry farms $(n=23)$ located in Beni-Suef and ElFayoum Provinces, Egypt, from May 2017 to December 2020. The investigated birds were freshly dead and/or diseased from gastrointestinal manifestations, mostly with whitish diarrhea in the examined poultry farms during the study period. The hygienic measures inside the investigated farms were slightly moderate.

\section{Samples Collection}

A total of 247 samples were collected aseptically from different internal organs (heart, liver, spleen, and caecum) of diseased and/or dead birds [chickens $(n=176)$, chicks $(n=47)$, ducks $(n=15)$, and ducklings $(n=9)]$. Aseptically, pieces of the heart, liver, spleen, and caecum were taken by sterile scissors. Then, collected samples were classified into two groups, heart, liver, and spleen, as one sample, while caecum was a separate sample to reduce the possibility of cross-contamination between samples (Cox et al., 2007). After labeling, each sample was added to $5 \mathrm{~mL}$ peptone water broth in screw-capped test tubes and transferred to the lab in a sterile icebox. Moreover, pre-enrichment, differential, and selective medium were used for isolation of the Salmonella species. The microbiological isolation and identification were performed according to ISO 6579 (2002).

\section{Isolation and Identification of Salmonella Species}

All samples were transferred in screw-capped test tubes containing peptone water $(1 \mathrm{~g}$ of samples on $9 \mathrm{~mL}$ peptone water) to the lab to be incubated at $37^{\circ} \mathrm{C}$ for 16-18h. Then, a loopful $(100 \mu \mathrm{L})$ was taken from each incubated peptone water broth to $9.9 \mathrm{~mL}$ Rappaport Vassiliadis broth and incubated at $42{ }^{\circ} \mathrm{C}$ for $24 \mathrm{~h}$. After that, a loopful from incubated Rappaport Vassiliadis broth was cultivated on MacConkey agar media, then pale colonies were taken and cultivated on XLD (Xylose lysine deoxycholate medium, Oxoid). Red colonies with a black center were cultivated on TSI (Triple sugar iron agar medium) and urease solution. Finally, colonies showed negative urease test and $R / Y$ with black ppt. on TSI were kept on tryptone soya agar medium. All isolated Salmonella spp. strains were identified using biochemical tests include TSI, urease test, Oxidase test, Indole test, Methyl red test, Voges Proskauer test, Citrate test, and Lysine iron agar test according to methods described by Quinn et al. (2002).

\section{Serotyping of Isolated Salmonella spp.}

According to Grimont \& Weill (2007), all Salmonellae were serologically identified in the Central Health Laboratories, Egypt, and Animal Health Research Institute Dokki, Giza, Egypt.

\section{Assessing the Effectiveness of Antimicrobial Agents Against Salmonella spp. Preparation of All Testing Agents Antimicrobial Agents}

Six antimicrobial classes of antibiotics were used: aminoglycosides (gentamicin, CN $10 \mu \mathrm{g}$ and tobramycin, TOB $10 \mu \mathrm{g}$ ), first-generation cephalosporin (cefazolin, KZ $30 \mu \mathrm{g}$ ), third-generation cephalosporins 
(cefotaxime, CTX $30 \mu \mathrm{g}$ ), phenicol (chloramphenicol, C $30 \mu \mathrm{g}$ ), penicillin (ampicillin, AMP $10 \mu \mathrm{g}$ ); monobactam (aztreonam, ATM $30 \mu \mathrm{g}$ ). The antimicrobial discs and Muller-Hinton agar were purchased from (Oxoid, UK).

\section{Essential Oils Used}

Four essential oils (EOs) include thymol, carvacrol, basil, and cinnamon oils, were used in the present study. Basil oil was extracted from the aerial parts of Ocimum basilicum collected from a flowering stage in the Naser region, Beni-Suef, Egypt, in March 2019. The method used to extract basil oil was hydro distillation using Clevenger type apparatus for $3 \mathrm{~h}$ (Elyemni et al., 2019). Anhydrous sodium sulfate was used during the dryness process, revealing the corresponding oil in $1.7 \%(\mathrm{~W} / \mathrm{W})$ then kept in a sealed vial at $4^{\circ} \mathrm{C}$. The extraction process was performed in the herbarium of the Department of Botany, College of Science, Minia University, Egypt. The other three essential oils were purchased from (SigmaAldrich, St. Louis, MO, USA) and used in different concentrations using ethanol to enhance oil solubility (Chen et al., 2014). Thymol, carvacrol, and cinnamon oils were prepared at $0.1,0.01$, and $0.001 \%$ concentrations; meanwhile, basil oil was prepared at $1.0 \%, 0.1 \%$, and $0.01 \%$ using the tenfold dilution method.

\section{Essential Oils Nano-emulsion}

Thymol, carvacrol, basil, and cinnamon oils nanoemulsion were performed using the Ultrasonication method as the method recommended by Pongsumpun et al. (2019). The formation of oil nano-emulsion was prepared in two steps. The first one is called "the oil phase" that includes the essential oil diluted into a certain concentration (thymol oil $0.01 \%$, carvacrol $0.001 \%$, basil $0.1 \%$, and cinnamon $0.01 \%$ ) then the second step was called "aqueous phase" that prepared by mixing Tween 80 3\% in distilled water thereafter, adding "oil phase" slowly on the "aqueous phase" (W/W) with mixing vigorously on a magnetic stirrer (MSH- 20D, WiseStir) at $500 \mathrm{rpm}, 25^{\circ} \mathrm{C}$ for $15 \mathrm{~min}$. to prepare a coarse emulsion. Nano-emulsion was obtained after mixing in the ultrasonic bath (Ultrasons, P-Selecta). The sonication was operated at a fixed operation frequency of $43 \mathrm{kHz}$, power output of $210 \mathrm{~W}$, and oscillation power at a high level. The ultrasound from the generator through a water bath was made at various temperatures $\left(25^{\circ} \mathrm{C}\right)$ and exposure times (10 mins).

\section{Characterization of Essential Oil Nano-emulsion}

All used essential oils nano-emulsion were characterized using FT-IR (Fourier Transform Infrared Spectrum; a JEOL JEM 2000EX) and TEM (Transmission electron microscopy, JEOL-JEM -2100). FT-IR spectra were measured at the Faculty of Postgraduate Studies of Advanced Science, Beni-Suef University, Egypt, as shown in Figures 1, 2, 3, and 4. Meanwhile, the images of HR-TEM were measured at National Research Center (NRC), Egypt, as shown in (Figures 5, 6, 7, and 8) respectively.

\section{Evaluating Methods}

The antimicrobial sensitivity pattern of tested antimicrobial agents against recovered Salmonella serovars was tested using the disc diffusion method (CLSI, 2016). In contrast, seven antimicrobial discs representing various antimicrobial classes of antibiotics were used. The minimum inhibitory concentration of essential oils with Salmonella serotypes was detected using the agar dilution method (Rusenova \& Parvanov, 2009). Furthermore, the agar dilution method as described by CLSI was used with some modification; a final concentration of $1 \%(\mathrm{v} / \mathrm{v})$ diluted oil was poured into the agar medium (Muller-Hinton agar) after autoclaving and cooled at $50^{\circ} \mathrm{C}$ after that, plates were dried at $37^{\circ} \mathrm{C}$ for $30 \mathrm{~min}$ prior to spot inoculation with $2 \mu \mathrm{L}$ aliquots of culture containing approximately $10^{4} \mathrm{CFU}$ of each organism. Inoculated plates were incubated at $37^{\circ} \mathrm{C}$ for $24 \mathrm{~h}$ for Salmonella spp. The MICs were determined as the lowest concentration of oil inhibiting the visible growth of each organism on the agar plate. To evaluate the effectiveness of oil nano-emulsion, the tested concentration of oil nano-emulsion $1 \%$ was added to the agar medium (M.H.A.) by applying the agar diffusion method (Rusenova \& Parvanov, 2009). After that, the interactive action between antimicrobial agents and both essential oils and oils nano-emulsion on resistant Salmonella serotypes showed the growth of Salmonellae using the disc diffusion method (CLSI, 2020) with some modifications in incorporation of essential oil $1 \%$ concentration $(\mathrm{V} / \mathrm{V})$ in the presence of seven antibiotic discs scattered on the agar medium after spreading of the microorganism.

\section{Statistical Analysis}

All data were prepared and analyzed using SPSS (statistical package for social sciences, version 22). The prevalence rate of Salmonella spp. and the frequency distribution of different serotypes of Salmonella isolates from the investigated birds and the effectiveness of different antimicrobial agents, tested essential oils, and oils nano-emulsions against all Salmonella serovars were analyzed using Chi-square test as a non-parametric test. The significance was confirmed at $\mathrm{p}<0.05$ for both parametric and non-parametric tests.

\section{RESULTS}

\section{The Prevalence Rate and Frequent Distribution of Different Serotypes of Salmonella spp.}

The overall prevalence rate of Salmonella spp. among the investigated birds was $20.24 \%$ (50/247). The highest prevalence rates of salmonellosis significantly appeared in ducklings, followed by chicks, chickens, and ducks at $\chi 2=15.21, \mathrm{p} \leq 0.05$ (Table 1 ).

The different serotypes of Salmonellae $(n=14)$ were obtained from each sample group and presented in Table 2. In Group A $(n=35)$, including heart, liver, and spleen revealed that $S$. Virchow was significantly detected in the highest percentage at $\chi 2=12.34, p \leq 0.05$ followed by $S$. infantis, $S$. anatum, S. paratyphi $C, S$. 
Table 1. Prevalence rate of Salmonella spp. species in different examined birds

\begin{tabular}{lccc}
\hline \multirow{2}{*}{$\begin{array}{c}\text { Examined } \\
\text { bird }\end{array}$} & \multicolumn{2}{c}{ Total } & Prevalence \\
\cline { 2 - 3 } & Examined No. & Positive No. & rate $(\%)$ \\
\hline Chickens & 176 & 31 & $17.61^{\mathrm{b}}$ \\
Chicks & 47 & 14 & 29.79 \\
Ducks & 15 & 2 & $13.33^{\mathrm{ab}}$ \\
Ducklings & 9 & 3 & $33.33^{\mathrm{a}}$ \\
Total & 247 & 50 & 20.24 \\
\hline
\end{tabular}

Note: The frequency distribution of Salmonella species among different investigated birds are significantly differed in the column with different superscripts $a, b$, \&ab $(p<0.05)$.

enteritidis, S. nanga, S. rechovot, S. salamae/ O6, 7: $\mathrm{m}, \mathrm{t}$, S. lumberhurst, S. montevideo, S. kedougou, S. salamael O6,7: g,m, $\{\mathrm{s}\}, \mathrm{t}: \mathrm{e}, \mathrm{n}, \mathrm{x}, \mathrm{S}$. typhimurium, and S. fillmore, respectively. In contrast, in group $\mathrm{B}(n=35)$ containing caecum showed that $S$. virchow, S. infantis, and S. paraTyphi $\mathrm{C}$ were found in the highest percentage, followed by $S$. anatum, $S$. rechovot, $S$. enteritidis, S. fillmore, $S$. nanga, S. kedougou, S. salamae/ O6,7: g,m, $\{\mathrm{s}\}, \mathrm{t}: \mathrm{e}, \mathrm{n}, \mathrm{x}, \mathrm{S}$. typhimurium, S. salamae/ O6, 7: $\mathrm{m}, \mathrm{t}, \mathrm{S}$. lumberhurst, and S. montevideo, respectively.

\section{FT-IR Spectrum and TEM Microscopy of Essential Oils Nano-Emulsion}

The morphological characterization of thymol and carvacrol, basil, and cinnamon oil nano-emulsion were determined using FT-IR spectra, as shown in Figures $1,2,3$, and 4 . It has been found that FT-IR spectrum of thymol nano-emulsion clarified the widened and smooth peak was noticed at $3331.25 \mathrm{~cm}^{-1}$ that confirm hydrophilic $(\mathrm{H}-\mathrm{OH})$ interaction in nano-emulsion besides to the other noticed peaks at 1646.34, 1086.55, and $619.29 \mathrm{~cm}^{-1}$ as were shown in Figure $1 \mathrm{~b}$. Meanwhile, FT-IR spectra of carvacrol nano-emulsion exhibited the characteristic peaks that appeared at 3333.92, 1646.56, 1043.12 , and $625.92 \mathrm{~cm}^{-1}$ (Figure 2b). On the other hand, basil essential oil showed variable peaks at 3379.45, 2923.95, 1514.98, 914.22, and $687.01 \mathrm{~cm}^{-1}$ (Figure 3a). In addition, FT-IR spectra of basil oil nano-emulsion appeared smooth peaks at 1669.16, 1118.83, 974.04, and $684.37 \mathrm{~cm}^{-1}$ (Figure $3 \mathrm{~b}$ ) that confirmed the formation of basil nano-emulsion. Moreover, FT-IR spectra of cinnamon oil (Figure 4a) showed the wide peak that appeared at 3350.96, 1647.34, 1047. 06, and $619.77 \mathrm{~cm}^{-1}$. In addition, cinnamon nano-emulsion exhibited similar peaks at 3328.33, 1647.74, 1044.17, and $618.64 \mathrm{~cm}-1$ (Figure $4 \mathrm{~b}$ ) that confirmed the success of nano-emulsion creation. Each thymol, carvacrol, basil, and cinnamon oil nano-emulsion were formulated by sonication for 20 min using thymol, carvacrol, water, and Tween 80 at a concentration of $3 \%$.

In contrast, the TEM microscopy of thymol nanoemulsion showed the morphological shape of nanoparticles (Figure 5a) that appeared as a spherical particle distributed in the TEM field. Whilst on the opposite side, the average diameter of nanoparticles ranged from 24.02 $\mathrm{nm}$ to $54.0 \mathrm{~nm}$ (Figure 5b). Furthermore, the TEM image
Table 2. Frequent distribution of different serotypes of Salmonella spp. isolates

\begin{tabular}{|c|c|c|c|}
\hline & Examined organs & $\begin{array}{l}\text { Heart, liver, } \\
\text { and spleen }\end{array}$ & Caecum \\
\hline \multirow{2}{*}{ Total } & Examined No. & 247 & 247 \\
\hline & Positive No. & 35 & 35 \\
\hline \multirow{14}{*}{ 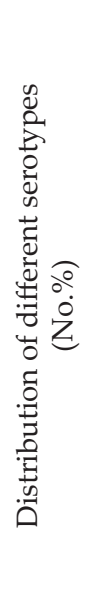 } & S. virchow & $6(17.14 \%)^{a}$ & $5(14.29 \%)^{a}$ \\
\hline & S. anatum & $4(11.43 \%)$ & $3(8.57 \%)$ \\
\hline & S. rehovot & $2(5.71 \%)$ & $3(8.57 \%)$ \\
\hline & S. enteritidis & $3(8.57 \%)$ & $2(5.71 \%)$ \\
\hline & S. salamae/ O6, 7: m, t & $2(5.71 \%)$ & $1(2.86 \%)$ \\
\hline & S. kedougou* & $1(2.86 \%)^{b}$ & $2(5.71 \%)^{b}$ \\
\hline & $\begin{array}{l}\text { S. salamae/ O6,7: g, m, } \\
\{\mathrm{s}\}, \mathrm{t}: \mathrm{e}, \mathrm{n}, \mathrm{x}\end{array}$ & $1(2.86 \%)$ & $2(5.71 \%)$ \\
\hline & S. lumberhurst & $2(5.71 \%)$ & $1(2.86 \%)$ \\
\hline & S. typhimurium & $1(2.86 \%)^{b}$ & $2(5.71 \%)^{b}$ \\
\hline & S. fillmore & $1(2.86 \%)$ & $2(5.71 \%)$ \\
\hline & S. montevideo & $2(5.71 \%)^{c}$ & $1(2.86 \%)^{\mathrm{c}}$ \\
\hline & S. paratyphic & $3(8.57 \%)$ & $4(11.43 \%)$ \\
\hline & S. infantis & $4(11.43 \%)$ & $5(14.29 \%)$ \\
\hline & S. nanga & $3(8.57 \%)$ & $2(5.71 \%)$ \\
\hline
\end{tabular}

Note: Means in the same column with different superscripts differ significantly $(\mathrm{p}<0.05)$

of carvacrol nano-emulsion showed the nanoparticles of spherical shape scattered into the nano-emulsion (Figure 6a). The nanoparticles' average size ranged from $0.03 \mu \mathrm{m}$ to $0.13 \mu \mathrm{m}$ (Figure 6b). TEM microscopy of basil nano-emulsion displayed the spherical and ovoid shapes of NPs scattered in the field of TEM (Figure 7a), with the average size ranged from $38.72 \mathrm{~nm}$ to 65.59 nm (Figure 7b). Finally, TEM microscopy of cinnamon nano-emulsion presented very fine spherical NPs in shape and had a raised surface (Figure 8a) besides the NPs size (Figure $8 b$ ) ranged from $53.21 \mathrm{~nm}$ to $54.30 \mathrm{~nm}$ in diameter.

\section{The Effectiveness of Antimicrobial Agents Against Salmonella Serovars}

The antimicrobial resistance profiles of Salmonella serovars are presented in Table 3. It has been found that Salmonella serovars exhibited their resistant patterns to ampicillin, chloramphenicol, gentamicin, followed by aztreonam, cefazolin, cefotaxime, and tobramycin, respectively.

To evaluate the effectiveness of thymol, carvacrol, basil, and cinnamon oils, MIC of essential oils and nanoemulsions against Salmonella serovars were detected and presented in Table 4 . The complete inhibitory effect of thymol oil was clarified at a concentration of $0.1 \%$. Whilst MIC of thymol oil for one Salmonella isolates at $0.01 \%$ concentration was $1.43 \%$. Meanwhile, thymol oil nano-emulsion at $0.01 \%$ exhibited no effect on the growth inhibition of Salmonellae. On the other hand, all Salmonella serotypes were highly inhibited after using carvacrol oil $0.1 \%(\mathrm{p}<0.05)$. The MIC of carvacrol was at $0.01 \%$ concentration in $34.29 \%$ Salmonella isolates. In contrast, carvacrol oil $0.001 \%$ in nano-emulsion showed that it did not affect all examined Salmonella serovars. 

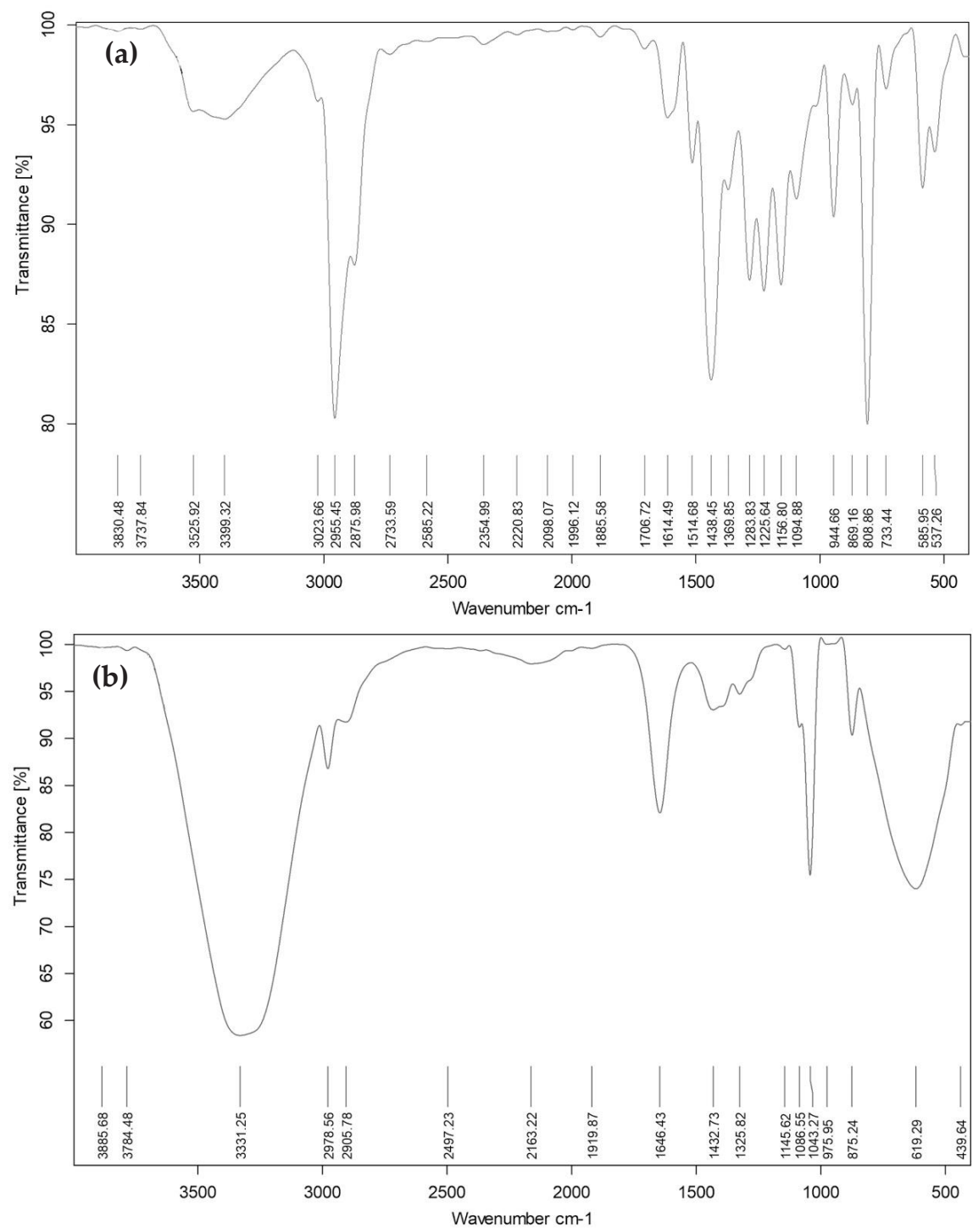

Figure 1. FT-IR spectra of thymol oil (a) at wavelength between 2955.45-585.95 $\mathrm{cm}^{-1}$ and thymol nano-emulsion (b) at strong infrared wavelength $\left(3331.25-619.29 \mathrm{~cm}^{-1}\right)$.

Table 3. Antibiotics sensitivity testing against all Salmonella spp. isolated from the investigated birds

\begin{tabular}{|c|c|c|c|c|c|c|c|}
\hline \multirow{3}{*}{ Antimicrobial agents } & \multirow{3}{*}{$\begin{array}{c}\text { Tested } \\
\text { concentration } \\
(\mu \mathrm{g})\end{array}$} & \multicolumn{6}{|c|}{ Antibiotics sensitivity testing against Salmonella spp. } \\
\hline & & \multicolumn{2}{|c|}{ Sensitive } & \multicolumn{2}{|c|}{ Intermediate } & \multicolumn{2}{|c|}{ Resistant } \\
\hline & & No. & $\%$ & No. & $\%$ & No. & $\%$ \\
\hline \multicolumn{8}{|l|}{ Aminoglycosides } \\
\hline Gentamicin $(\mathrm{CN})$ & 10 & 42.0 & 60.0 & 6.0 & 8.57 & 22.0 & 31.43 \\
\hline Tobramycin (TOB) & 10 & 46.0 & 65.71 & 9.0 & $12.86^{\mathrm{a}}$ & 15.0 & $21.43^{\mathrm{b}}$ \\
\hline \multicolumn{8}{|l|}{ Phenicol's } \\
\hline Chloramphenicol (C) & 30 & 39.0 & 55.71 & 3.0 & $4.29^{\mathrm{b}}$ & 28.0 & 40.0 \\
\hline \multicolumn{8}{|l|}{ Penicillin's } \\
\hline Ampicillin (AMP) & 10 & 35.0 & $50.0^{\mathrm{b}}$ & 2.0 & $2.86^{\mathrm{c}}$ & 33.0 & $47.14^{\mathrm{a}}$ \\
\hline \multicolumn{8}{|l|}{$\begin{array}{l}\text { Cephems (parenteral) in- } \\
\text { cluding cephalosporins }\end{array}$} \\
\hline Cefotaxime (CTX) & 30 & 48.0 & 68.57 & 7.0 & 10.0 & 15.0 & $21.43^{\mathrm{b}}$ \\
\hline Cefazolin (KZ) & 30 & 55.0 & $78.57^{\mathrm{a}}$ & 0.0 & 0.0 & 15.0 & $21.43^{\mathrm{b}}$ \\
\hline \multicolumn{8}{|l|}{ Monobactams } \\
\hline Aztreonam (ATM) & 30 & 47.0 & 67.14 & 5.0 & 7.14 & 18.0 & 25.71 \\
\hline
\end{tabular}

Note: Total examined isolates $(\mathrm{n}=70)$; No.= Number of positive Salmonellae. The sensitivity pattern of Salmonella spp. serotypes to antimicrobial agents was significantly differed differed in the same column with different superscripts at $p<0.05$. 

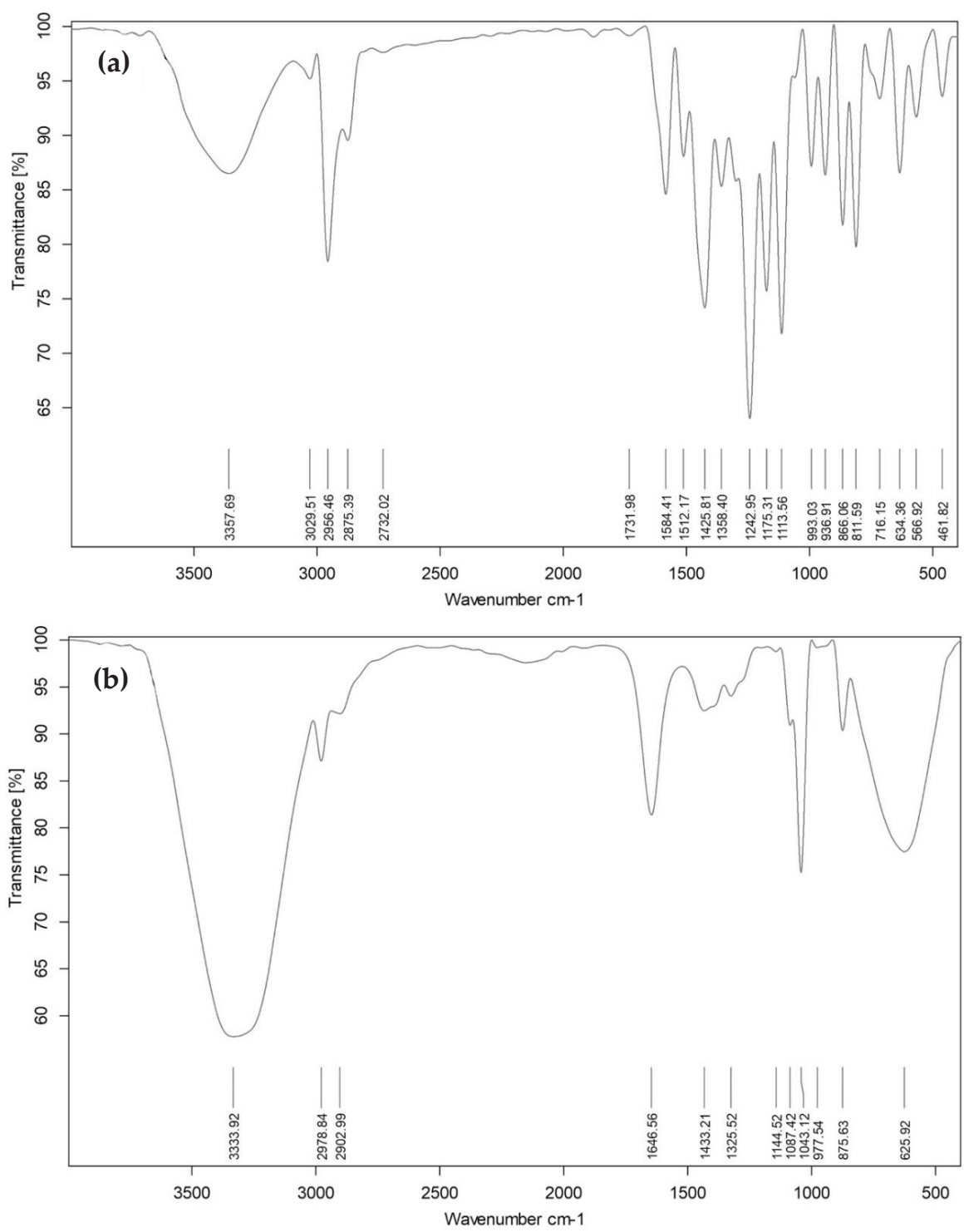

Figure 2. FT-IR spectra of carvacrol oil (a) at infrared wavelength 2996.45- $566.92 \mathrm{~cm}^{-1}$, meanwhile infrared wave of carvacrol nano-emulsion (b) was 333.92-625.92 $\mathrm{cm}^{-1}$.

Table 4. The antimicrobial effect of different essential oils and oils nano-emulsion against Salmonella spp. isolates

\begin{tabular}{|c|c|c|c|c|c|}
\hline \multirow{3}{*}{ Essential oils } & \multirow{3}{*}{$\begin{array}{c}\text { Tested conc. } \\
\text { (\%) }\end{array}$} & \multicolumn{4}{|c|}{ Sensitivity of Salmonella spp. to tested oils and oils nano-emulsion } \\
\hline & & \multicolumn{2}{|c|}{ Sensitive } & \multicolumn{2}{|c|}{ Resistant } \\
\hline & & No. & $\%$ & No. & $\%$ \\
\hline \multirow[t]{3}{*}{ Thymol oil } & 0.1 & 70 & 100 & 0.0 & 0.0 \\
\hline & 0.01 & 1.0 & 1.43 & 69 & $98.57^{a}$ \\
\hline & 0.001 & 0.0 & 0.0 & 70 & 100.0 \\
\hline Thymol oil nano-emulsion & 0.01 & 0.0 & 0.0 & 70 & 100.0 \\
\hline \multirow[t]{3}{*}{ Carvacrol oil } & 0.1 & 70 & 100.0 & 0.0 & 0.0 \\
\hline & 0.01 & 24 & 34.29 & 46 & $65.71^{c}$ \\
\hline & 0.001 & 0.0 & 0.0 & 70 & 100.0 \\
\hline Carvacrol oil nano-emulsion & 0.001 & 0.0 & 0.0 & 70 & 100.0 \\
\hline \multirow[t]{3}{*}{ Basil oil } & 1.0 & 70 & 100.0 & 0.0 & 0.0 \\
\hline & 0.1 & 12 & 17.14 & 58 & $82.86^{\mathrm{b}}$ \\
\hline & 0.01 & 0.0 & 0.0 & 70 & 100.0 \\
\hline Basil oil nano-emulsion & 0.1 & 0.0 & 0.0 & 70 & 100.0 \\
\hline \multirow[t]{3}{*}{ Cinnamon oil } & $0.1 \%$ & 70 & 100.0 & 0.0 & 0.0 \\
\hline & $0.01 \%$ & 8.0 & 11.43 & 62 & 88.57 \\
\hline & $0.001 \%$ & 0.0 & 0.0 & 70 & 100.0 \\
\hline Cinnamon oil nano-emulsion & $0.01 \%$ & 0.0 & 0.0 & 70 & 100.0 \\
\hline
\end{tabular}

Note: Total examined isolates ( $\mathrm{n}=70)$; No.= Number of positive Salmonellae. The sensitivity pattern of Salmonella spp. to tested oils and oils nano-emulsion was significantly declared in the same column with different superscripts at $\mathrm{p}<0.05$. 

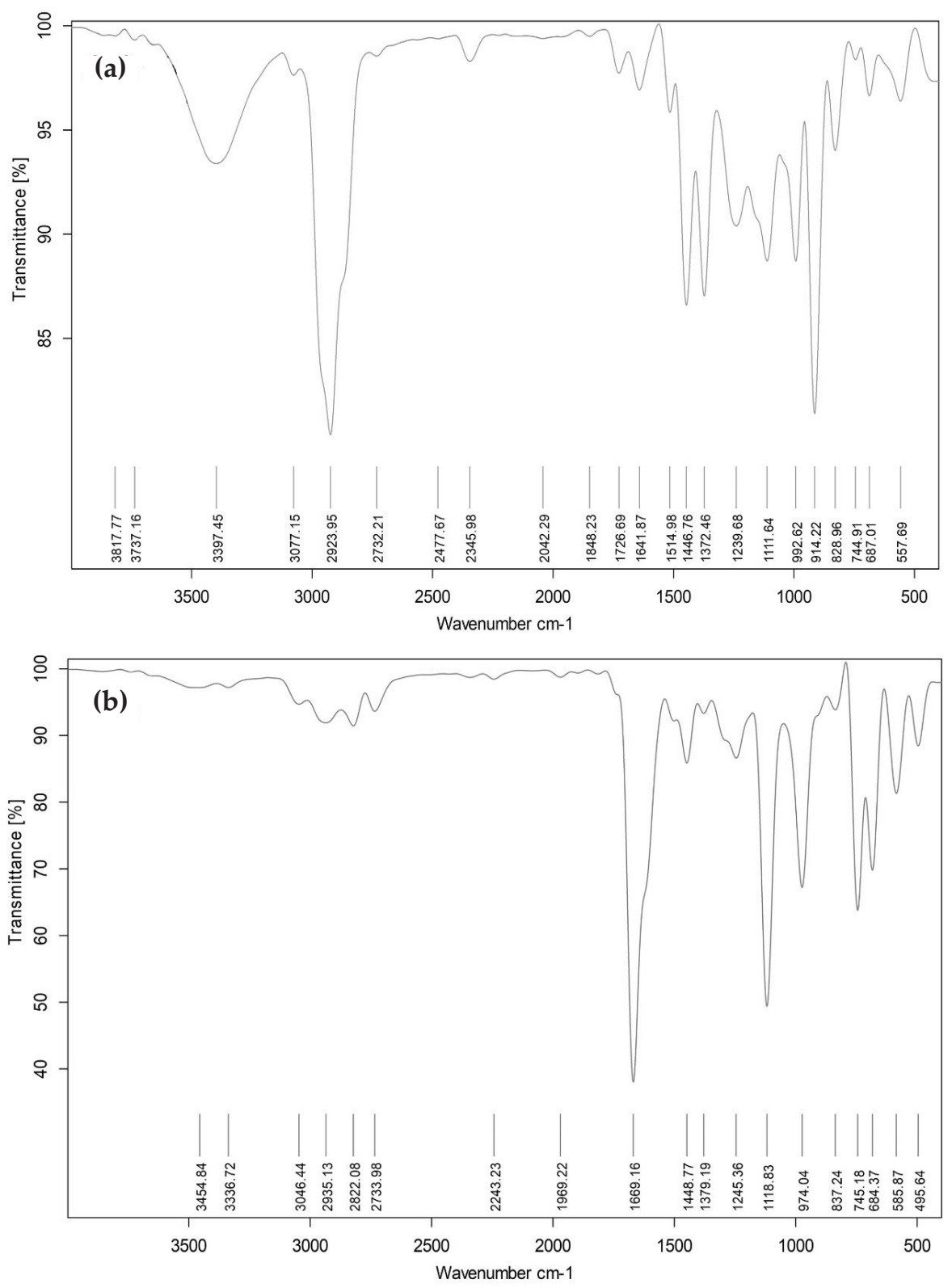

Figure 3. FT-IR spectra of basil oil (a) at infrared wavelength $2923.95-914.22 \mathrm{~cm}^{-1}$ and basil nano-emulsion (b) clarified at wavelength $1669.16-585.87 \mathrm{~cm}^{-1}$.

Whilst basil oil $1.0 \%$ was completely effective against Salmonellae. In addition, basil oil $0.1 \%$ was effective against $17.14 \%$ of the tested isolates. Otherwise, the effect of nano-emulsion form not appeared on Salmonella serovars under examination. Salmonella serovars were completely inhibited with cinnamon oil $0.1 \%$, while $11.43 \%$ of Salmonella spp. were inhibited at $0.01 \%$ of cinnamon oil. However, the nano-emulsion form did not affect Salmonella isolates. Oppositely, the effect of essential oils and oils nano-emulsion interactive with antimicrobial agents on resistant Salmonella serotypes was clarified (Table 5). All resistant Salmonella serotypes to gentamicin, tobramycin, chloramphenicol and cefazolin became completely sensitive after using thymol, carvacrol, basil, and cinnamon oils in the media. On the other hand, $11.43 \%$ of Salmonella serotypes were still resistant to ampicillin after using essential oils (thymol, carvacrol, basil, and cinnamon oils). In addition, thymol, carvacrol, basil, and cinnamon oils enhanced the susceptibility of resistant Salmonellae to cefotaxime except in some isolates under test at $7.14 \%, 7.14 \%, 14.28 \%$, and $7.14 \%$, respectively. Moreover, they enhanced the susceptibility of resistant Salmonellae to aztreonam except in some isolates under test at $17.14 \%, 18.57 \%, 20 \%$, and $18.57 \%$, respectively. The interaction between antimicrobial agents and nano-emulsion form of essential oils revealed a complete enhanced effect of essential oils in nano-emulsion form to Salmonellae against cefotaxime. Furthermore, the lethal effect of thymol, carvacrol, basil, and cinnamon nano-emulsion was detected when interactive with aztreonam against Salmonella spp. except $83.33 \%, 76.92 \%, 71.43 \%$, and $76.92 \%$, respectively of the examined isolates. Whilst there is no enhancement in susceptibility of Salmonella serotypes to ampicillin as displayed in Table 6. 

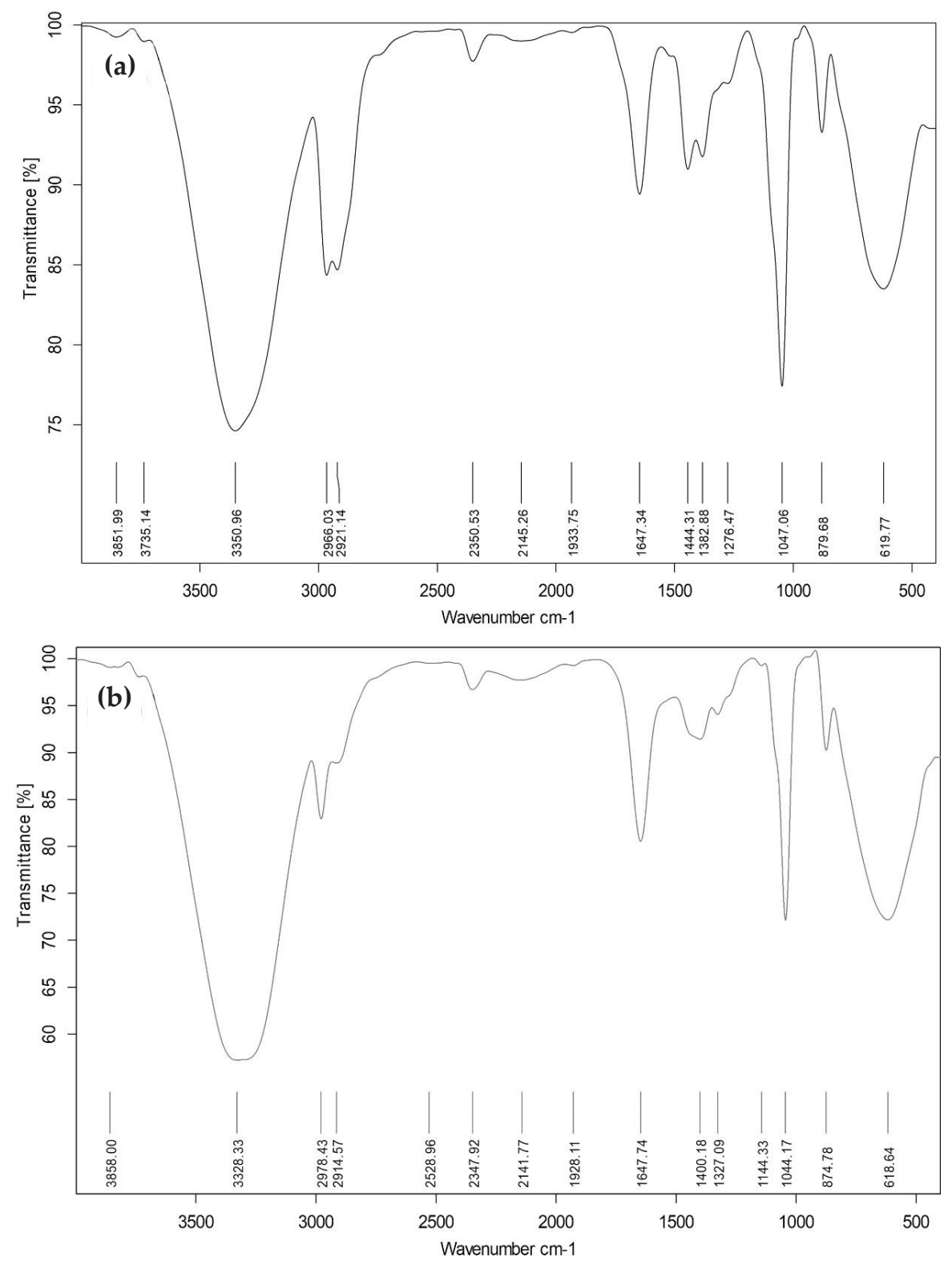

Figure 4. FT-IR spectra of cinnamon oil (a) at infrared wavelength $3350.96-619.71 \mathrm{~cm}^{-1}$ and infrared wavelength of cinnamon nano-emulsion (b) was 3328.33-618.64 $\mathrm{cm}^{-1}$
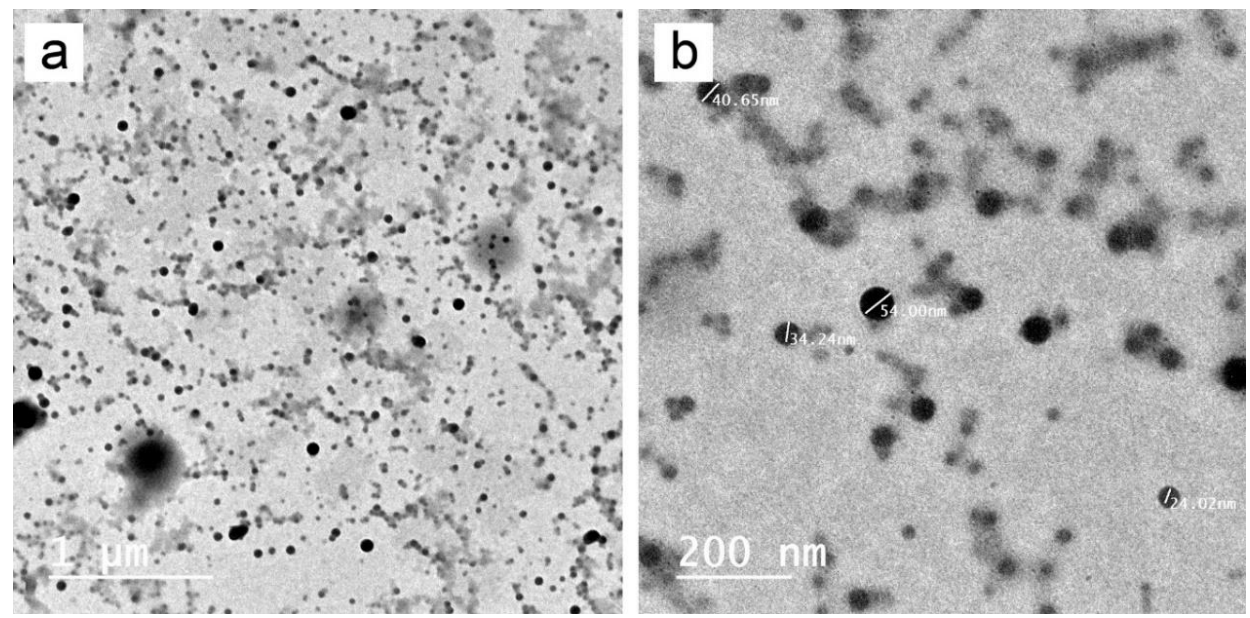

Figure 5. Transmission electron microscopy (TEM) of thymol oil nano emulsion (a-b) showed the morphological shape of nanoparticles (a) that appeared as a fine spherical particle distributed in the TEM field, and the average diameter of nanoparticles (b) is ranged from 24.02 to $54.0 \mathrm{~nm}$ 

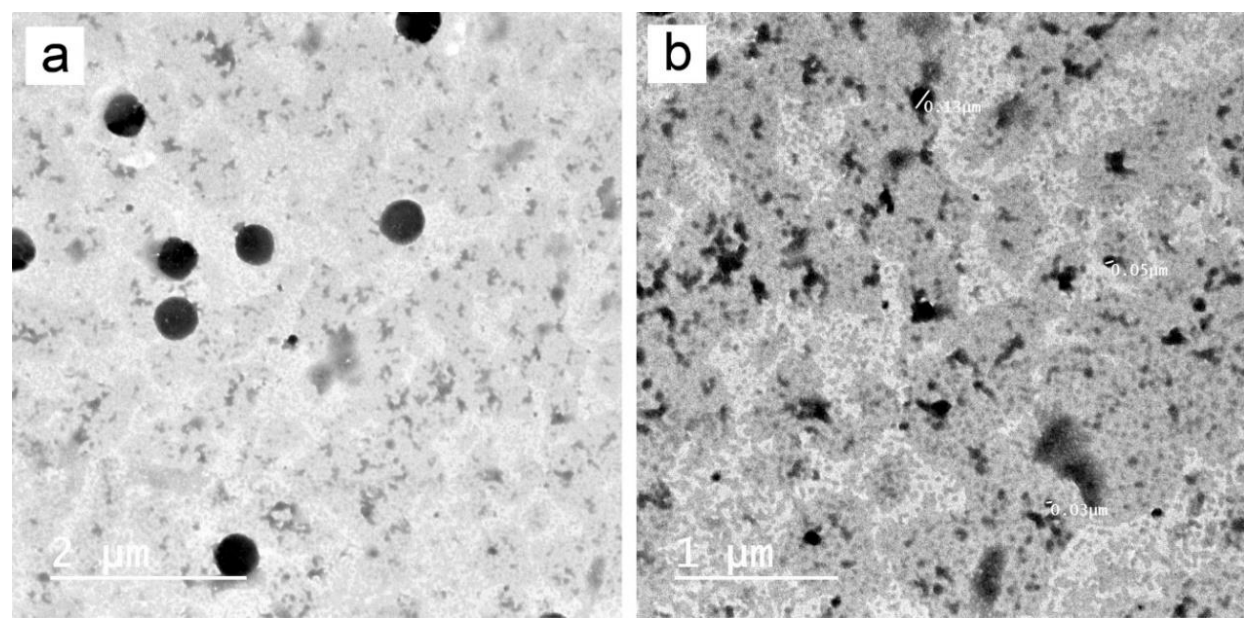

Figure 6. Transmission electron microscopy (TEM) of carvacrol oil nano-emulsion (a-b) revealed the nanoparticles of spherical shape scattered into the nano-emulsion (a), and the average size of nanoparticles is ranged from 0.03 to $0.13 \mu \mathrm{m}$ as shown in (b).
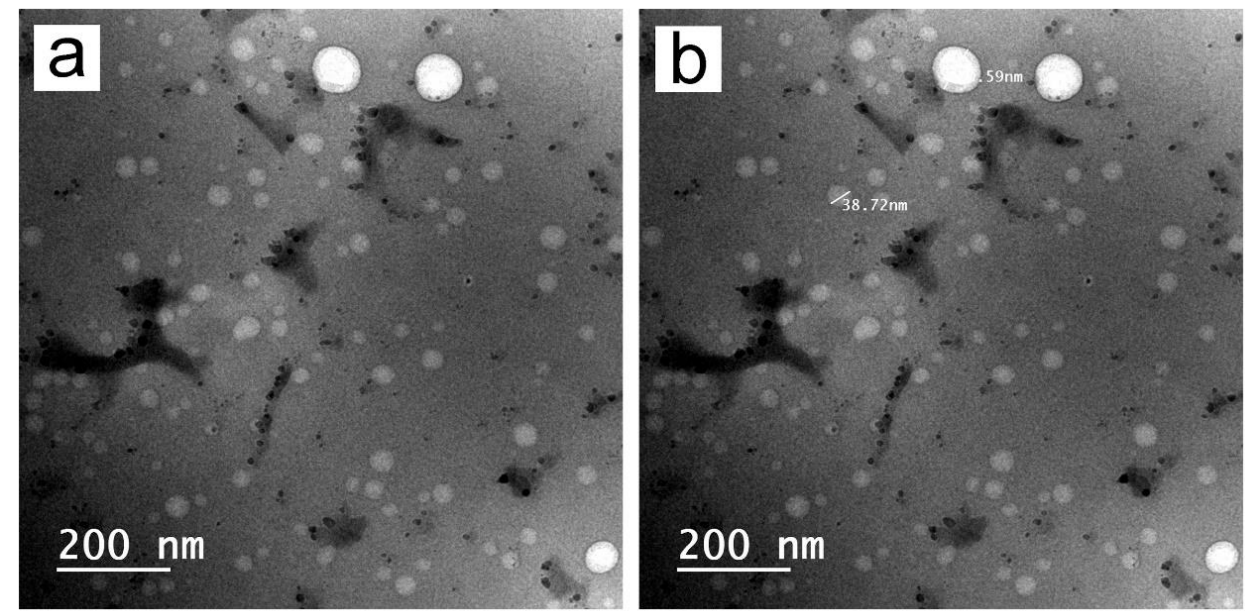

Figure 7. Transmission electron microscopy (TEM) of basil oil nano-emulsion (a-b) displayed the spherical and ovoid shape of NPs scattered in the field of TEM (a) with the average size is ranged from 38.72 to $65.59 \mathrm{~nm}$ (b).
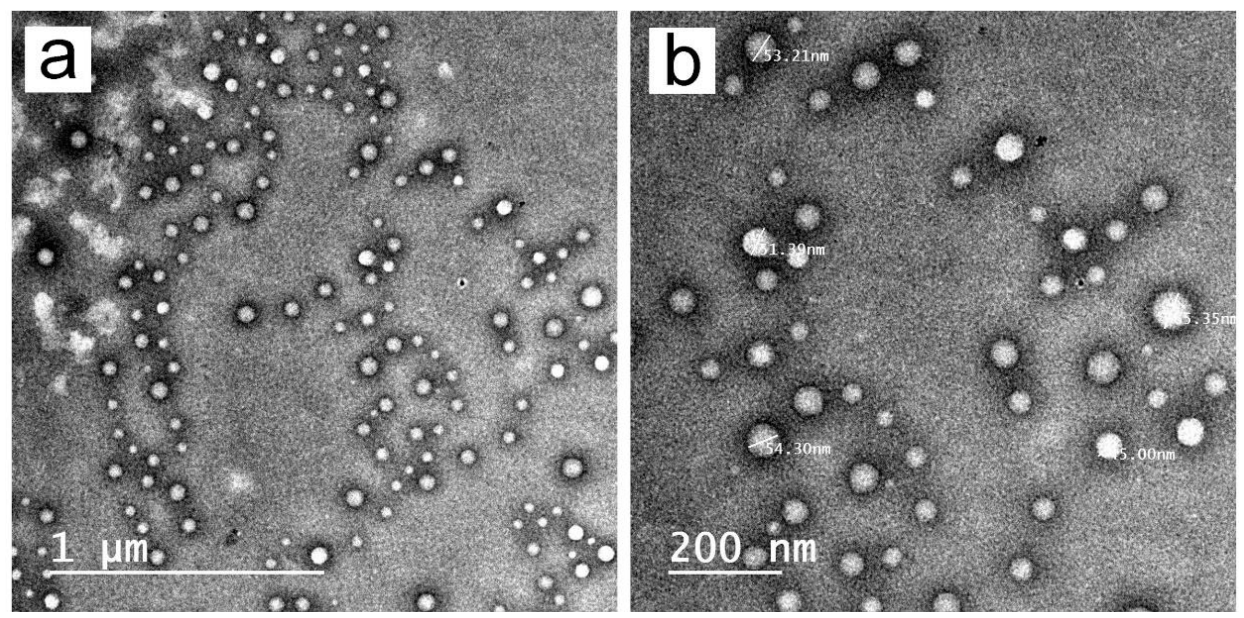

Figure 8. Transmission electron microscopy (TEM) of cinnamon oil nano-emulsion (a-b) presented very fine spherical NPs in shape and had a raised surface (a) besides the NPs size (b) is ranged from 53.21 to $54.30 \mathrm{~nm}$ in diameter. 


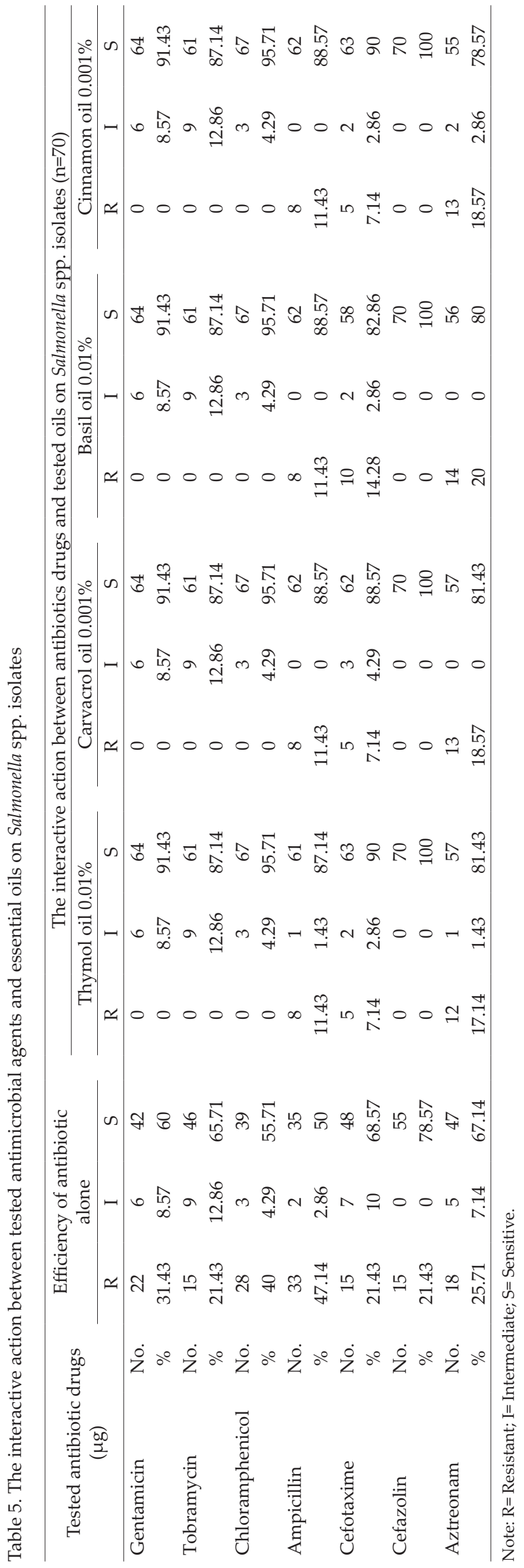

\section{DISCUSSION}

The monitoring and tracking of different Salmonella serotypes in investigated poultry farms with different bird species and ages were considered the milestone for controlling bacterial infections. During this study, the highest prevalence rates of salmonellosis appeared in ducklings and chicks, followed by chickens and ducks that might be attributed to the absence of sanitation and hygienic measures among poultry farms (EFSA et al., 2019). Whilst Ahmed et al. (2019) found that the total prevalence rate of Salmonella infection was $6.4 \%$ in poultry farms. The prevalence rate of Salmonellae recovered from chicks was 7.5\% (Sedeik et al., 2019); meanwhile, in chickens was $13.6 \%$ (Elsotohy, 2019). Oppositely, the prevalence rate of Salmonella spp. in ducks during this study was lower than recorded by Eid (2019). In addition, EFSA et al. (2019) recorded the distribution of variable Salmonella serovars among poultry, including $S$. enteritidis, S. typhimurium, S. virchow, and S. infantis.

The morphological characterization of thymol nano-emulsion by FT-IR revealing the widest peak at $3331.25 \mathrm{~cm}^{-1}$ with spherical particles and average size from $24.02 \mathrm{~nm}$ to $54.0 \mathrm{~nm}$ was detected through TEM in a parallel line with $\mathrm{Wu}$ et al. (2012) and Kumari et al. (2018). While thymol nano-emulsion using chitosan was characterized by nanoparticles ranged from 117$250 \mathrm{~nm}$ (Sotelo-boy's et al., 2015). In addition, carvacrol oil nano-emulsion exhibited spherical particles with $30-130 \mathrm{~nm}$ in size. Besides, wide peaks appeared at $3333.92 \mathrm{~cm}^{-1}$, similar to the result reported by Wu et al. (2012). Furthermore, FT-IR of cinnamon nano-emulsion revealed the widest peak at a frequency range of 450$4000 \mathrm{~cm}^{-1}$ with the highest peak at $3328.33 \mathrm{~cm}^{-1}$, and TEM microscopy showed spherical shape particles with diameter size ranged from 38.72 to $65.59 \mathrm{~nm}$ that was in line with the results reported by Ghosh et al. (2013). Additionally, Medhat et al. (2019) and Hussein et al. (2017) observed that the particles of carvacrol nanoemulsion are very fine and small (less than $50 \mathrm{~nm}$ in diameter), and the nano size of carvacrol was stabilized against aggregation. The effectiveness of oil nano-emulsion against Salmonella isolates exhibited lower decimal reduction concentrations than using essential oils in its form, which is a parallel way with Ahmed et al. (2017). The recovered Salmonella serotypes were exposed to six antimicrobial classes of antibiotics of public health concern to assess the susceptibility patterns. The obtained results showed that the higher resistance pattern of Salmonella spp. to both gentamicin and chloramphenicol was attributed to overuse and/ or misuse of antibiotics (Bertrand \& Hocquet, 2011; Wibisono et al., 2020). While Badr et al. (2015) found that Salmonella serovars were completely sensitive to gentamicin and chloramphenicol in opposite to our results revealed resistance with $31.43 \%$ and $40 \%$ to the same antibiotics. Otherwise, the complete resistance of Salmonellae recorded by Ahmed et al. (2019) against ampicillin, cefotaxime, and aztreonam had a highly diverse opinion upon our resistance profile to the same antibiotics represented by $47.14 \%$, $21.43 \%$, and $25.71 \%$, respectively. The sensitivity pattern of Salmonella spp. to four essential oils, including 
Table 6. The sensitivity testing of resistant Salmonella spp. to essential oils, oils nano-emulsion, and antimicrobial agents

\begin{tabular}{|c|c|c|c|c|}
\hline \multirow{3}{*}{$\begin{array}{l}\text { Essential oils/ } \\
\text { nano-emulsion }\end{array}$} & & \multicolumn{3}{|c|}{$\begin{array}{l}\text { The sensitivity pattern of resistant Salmonella spp. to tested essential oils, oils nano- } \\
\text { emulsion, and antimicrobial agents }\end{array}$} \\
\hline & & Ampicillin (AMP) & Cefotaxime (CTX) & Aztreonam (ATM) \\
\hline & & & & \\
\hline \multirow[t]{3}{*}{ Thymol oil $0.01 \%$} & Alone & 8.0 & 5.0 & 12.0 \\
\hline & Nano-emulsion & 8.0 & 0.0 & 10.0 \\
\hline & $\%$ & 100 & 0.0 & 83.33 \\
\hline \multirow[t]{3}{*}{ Carvacrol $0.001 \%$} & Alone & 8.0 & 5.0 & 13.0 \\
\hline & Nano-emulsion & 8.0 & 0.0 & 10.0 \\
\hline & $\%$ & 100 & 0.0 & 76.92 \\
\hline \multirow[t]{3}{*}{ Basil 0.1\% } & Alone & 8.0 & 10.0 & 14.0 \\
\hline & Nano-emulsion & 8.0 & 0.0 & 10.0 \\
\hline & $\%$ & 100 & 0.0 & 71.43 \\
\hline \multirow[t]{3}{*}{ Cinnamon $0.01 \%$} & Alone & 8.0 & 5.0 & 13.0 \\
\hline & Nano-emulsion & 8.0 & 0.0 & 10.0 \\
\hline & $\%$ & 100 & 0.0 & 76.92 \\
\hline
\end{tabular}

thymol, carvacrol, basil, and cinnamon were tested to overcome the multidrug resistance pattern of Salmonella spp. isolates during the study and avoiding the residue hazards of antimicrobial agents in the poultry carcasses. Regarding the chemical structure of thymol and carvacrol, causing changes in the structure of Gram-negative bacteria, including Salmonella spp. (Guarda et al., 2011; Van de Vel et al., 2019). Furthermore, the antimicrobial activity of carvacrol and thymol oil was significantly high against Salmonella strains. These results were in parallel with Du et al. (2015) and Boskovic et al. (2016). Moreover, the antimicrobial activity of carvacrol against Salmonellae was higher than that of Ocimum basilicum and thymol oils, whereas these results agreed with the result reported by Soković et al. (2010). On the contrary, the antimicrobial activity of thymus and oregano oils was high which might be due to their high content of phenol components (Soković et al., 2010). The low water solubility of different essential oils leads to limitations in their antimicrobial activities. Therefore, using the disc diffusion method was not concerned in the current study with the essential oils used, whereas the study was agreed with Soković et al. (2010). Oppositely, the effect of essential oils and oils nano-emulsion interactive with antimicrobial agents on resistant Salmonella serotypes was clarified that all resistant Salmonella serotypes to gentamicin, tobramycin, chloramphenicol, and cefazolin became completely sensitive after using thymol, carvacrol, basil, and cinnamon oils in media. These results were in line with Idris et al. (2015), who found that thymol and carvacrol oils had a potent inhibitory effect against Salmonella spp. besides, the inhibitory effect of encapsulated nano thymol and carvacrol oil against Salmonellae was high. In this context, thymol, carvacrol, basil, and cinnamon oils revealed that the ability to enhance the susceptibility of resistant Salmonellae to cefotaxime except some Salmonella isolates as the results recorded by Ribeiro et al. (2020), who proved that the highest synergistic activity between basil and oregano oils conjugated with cefotaxime in inhibition of Gramnegative bacteria. In our study, the interaction between antimicrobial agents and oils nano-emulsion revealed a complete enhanced effect of oils nano-emulsion on Salmonellae against cefotaxime. Furthermore, the lethal effect of thymol, carvacrol, basil, and cinnamon nanoemulsion was detected when interactive with aztreonam against Salmonella spp. From the obtained results, it has been found that the interactive action between each essential oil, oil nano-emulsion with different antimicrobial agents was considered the upcoming promising for control of Salmonella infection at the farm level. In addition, reinforcing hygienic measures inside the investigated farms could minimize the risk of Salmonella infection. So, further studies are needed to evaluate the in-vivo usage of oils nano-emulsion for control of Salmonella serotypes and to ensure their suitability as an alternative to antimicrobial agents for the control of bacterial infections.

\section{CONCLUSION}

This study verified the wide distribution of different Salmonella serovars of zoonotic importance among poultry farms, including $S$. virchow, $S$. typhimurium, and $S$. infantis. Furthermore, the resistance pattern of Salmonella spp. to both gentamicin and chloramphenicol was higher than other tested antimicrobial agents. Using essential oils is operative sufficiently against Salmonella spp. infection to avoid multidrug resistance. Oppositely, essential oils nanoemulsion exhibited a low effect in growth inhibition of Salmonellae. Still, the interaction with antimicrobial agents helps enhance Salmonellae susceptibility to the different tested antimicrobial agents.

\section{CONFLICT OF INTEREST}

All authors declare that there is no conflict of interest during this work.

\section{ACKNOWLEDGEMENT}

The authors represent all express gratitude to their Department for the technical support during the study 
period. This work did not receive any financial funding from any organizations.

\section{REFERENCES}

Ahmed, A. O., M. A. Raji, P. H. Mamman, C. N. Kwanashie, I. A. Raufu, A. Aremu, \& G. J. Akorede. 2019. Salmonellosis: Serotypes, prevalence, and multi-drug resistant profiles of Salmonella enterica in selected poultry farms, Kwara State, North Central Nigeria. Onderstepoort J. Vet. Res. 86:1-8. https://doi.org/10.4102/ojvr.v86i1.1667

Ahmed, J., N. Hiremath, \& H. Jacob. 2017. Antimicrobial efficacies of essential oils/ nanoparticles incorporated polylactide films against L. monocytogenes and S. typhimurium on contaminated cheese. Int. J. Food Prop. 20:53-67. https:// doi.org/10.1080/10942912.2015.1131165

Badr, H., M. A. A. Abdel Rahman, E. M. Farghaly, A. Gaber, H. Roshdy, \& S. A. Nasef. 2015. Characterization of some aerobic bacterial microorganism isolated from newly hatched imported ducklings. Egypt. Poult. Sci. J. 35:1123-1136.

Bertrand, X. \& D. Hocquet. 2011. Antibiotic drug resistance: Causes and solutions. EJHP practice. 17: 58-59.

Boskovic, M., N. Zdravkovic, J. Ivanovic, J. Djordjevic, J. Janjic, N. Pavlicevic, \& M. Z. Baltic. 2016. Inhibitory effect of thyme and oregano essential oils and some essential oil components on Salmonella Senftenberg and Salmonella Give. Meat technol. 57:67-71.

Chen, H., P. M. Davidson, \& Q. Zhong. 2014. Impacts of sample preparation methods on solubility and antilisterial characteristics of essential oil components in milk. Appl. Environ. Microbiol. 80:907-916. https://doi.org/10.1128/ AEM.03010-13

Chouhan, S., K. Sharma, \& S. Guleria. 2017. Antimicrobial activity of some essential oils-present status and future perspectives. Medicines 4:58. https://doi.org/10.3390/ medicines 4030058

CLSI. 2020. M100 Performance Standards for Antimicrobial Susceptibility Testing. M100S. $30^{\text {th }}$ ed. Clinical and Laboratory Standards Institute, USA. https://clsi.org/media/3481/m100ed30_sample.pdf.

Cole, E. R., R. B. dos Santos, V. Lacerda Júnior, J. Martins, S. Greco, \& A. Cunha Neto. 2014. Chemical composition of essential oil from ripe fruit of Schinus terebinthifolius raddi and evaluation of its activity against wild strains of hospital origin. Braz. J. Microbiol. 45:821-828. https://doi. org/10.1590/S1517-83822014000300009

Cox, N. A., L. J. Richardson, R. J. Buhr, J. K. Northcutt, J. S. Bailey, P. F. Cray, \& K. L. Hiett. 2007. Recovery of Campylobacter and Salmonella serovars from the spleen, liver and gallbladder and ceca of six- and eight-week-old commercial broilers. J. Appl. Poult. Res. 16:477-480. https://doi. org/10.3382/japr.2006-00123

Du, E., L. Gan, Z. Li, W. Wang, D. Liu, \& Y. Guo. 2015. In vitro antibacterial activity of thymol and carvacrol and their effects on broiler chickens challenged with Clostridium perfringens. J. Anim. Sci. biotechnol. 6:1-12. https://doi. org/10.1186/s40104-015-0055-7

EFSA Panel on Biological Hazards (EFSA BIOHAZ Panel), K. Koutsoumanis, A. Allende, A. Alvarez-Ordonez, D. Bolton, S. Bover-Cid, M. Chemaly, A. De Cesare, L. Herman, F. Hilbert, R. Lindqvist, M. Nauta, L. Peixe, G. Ru, M. Simmons, P. Skandamis, E. Suffredini, J. Dewulf, T. Hald, V. Michel, T. Niskanen, A. Ricci, E. Snary, F. Boelaert, W Messens, \& R. Davies. 2019. Salmonella control in poultry flocks and its public health impact. E. J. EFSA. 17:5596. https://doi.org/10.2903/j.efsa.2019.5596

Eid, S. 2019. Free ranging household ducks, an overview on enteric bacterial and parasitic infections. Assiut Vet. Med. J. 65:150-170. https://doi.org/10.21608/avmj.2019.168994
Elshafie, H.S., N. Ghanney, S.M. Mang, A. Ferchichi, \& I. Camele. 2016. An in vitro attempt for controlling severe phytopathogens and human pathogens using essential oils from mediterranean plants of genus schinus. J. Med. Food. 19:266-273. https://doi.org/10.1089/jmf.2015.0093

Elsotohy, M. E. M. 2019. Molecular characterization of Salmonella Enterica isolated from broilers. Thesis (PH.D.). Department of Bacteriology, Immunology and Mycology, Faculty of Veterinary Medicine, Suez Canal University, Egypt. p. 166.

Elyemni, M., B. Louaste, I. Nechad, T. Elkamli, A. Bouia, M. Taleb, M. Chaouch, \& N. Eloutassi. 2019. Extraction of essential oils of Rosmarinus officinalis L.by two different methods: Hydrodistillation and microwave assisted hydrodistillation. Sci. World J. https://doi.org/10.1155/2019/3659432

European Food Safety Authority (EFSA), \& European Centre for Disease Prevention and Control, (ECDC). 2016. The European Union summary report on trends and sources of zoonoses, zoonotic agents and food-borne outbreaks in 2014. EFSA J. 13:4329. https://doi.org/10.2903/j. efsa.2015.4329

Ghosh, V., S. Saranya, A. Mukherjee, \& N. Chandrasekaran. 2013. Cinnamon oil nanoemulsion formulation by ultrasonic emulsification: investigation of its bactericidal activity. J. Nanosci. 13:114-122. https://doi.org/10.1166/ jnn.2013.6701

Grimont, P. A. \& F. Weill. 2007. Antigenic formulas of the Salmonella serovars. $9^{\text {th }}$ ed. WHO, Collaborating Centre for Reference and Research on Salmonella, Paris, France.

Guarda, A., J.F. Rubilar, J. Miltz, \& M. J. Galotto. 2011. The antimicrobial activity of microencapsulated thymol and carvacrol. Int. J. Food Microbiol. 146: 144-150. https://doi. org/10.1016/j.ijfoodmicro.2011.02.011

Guibourdenche, M., P. Roggentin, M. Mikoleit, P. I. Fields, J. Bockemiihl, P. A. D. Grimont, \& F. Weill. 2010. Supplement 2003-2007 (No.47) to the white-KauffmannLe Minor scheme. Res. Microbiol. 161:26-29. https://doi. org/10.1016/j.resmic.2009.10.002

Hendriksen, R. S., A. R. Vieira, S. Karlsmose, D. M. A. L. F. Wong, A. B. Jensen, H. C. Wegener, \& F. M. Aarestrup. 2011. Global monitoring of Salmonella serovar distribution from the World Health Organization global foodborne infections network country data bank: Results of quality assured laboratories from 2001 to 2007. Foodborne Pathog. Dis. 8:887-900. https://doi.org/10.1089/fpd.2010.0787

Hessen, A. H. A. 2006. Evaluation of Organic Acids in Prevention and Control of Paratyphoid Infection in Chicken Flocks. Theses (M.V.Sc.). Department of Avian and Rabbit Medicine, Faculty of Veterinary Medicine, Zagazig University, Egypt. p.125.

Hossain, M. A., M. R. Amin, M. D. I. Khan, M. L. Mollah, \& M. A. Amin. 2015. Occurrences, treatment, and antibiotic resistant pattern of colibacillosis and salmonellosis in broiler. J. Biosci. Agric. Res. 4:67-73. https://doi.org/10.18801/ jbar.040215.44

Hussein, J., M. El-Bana, E. Refaat, \& M. E. El-Naggar. 2017. Synthesis of carvacrol-based nanoemulsion for treating neurodegenerative disorders in experimental diabetes. J. Funct. Foods. 37:441-448. https://doi.org/10.1016/j. jff.2017.08.011

Idris, M., U. Huzaifa, H. Hamisu, \& S. Zubaida. 2015. Nanoencapsulation of essential oils with enhanced antimicrobial activity: A new way of combating antimicrobial resistance. J. Pharmacogn. Phytochem. 4:165-170.

ISO 6579. 2002. E $4^{\text {th }}$ ed. Microbiology - General guidance on methods for the detection of Salmonella, International Organization for Standardization, Geneve, Switzerland.

Kumari S., R. V. Kumaraswamy, R. C. Choudhary, S. S. Sharma, A. Pal, R. Raliya, P. Biswas, \& V. Saharan. 
2018. Thymol nanoemulsion exhibits potential antibacterial activity against bacterial pustule disease and growth promotory effect on soybean. Sci. Rep. 8:6650. https://doi. org/10.1038/s41598-018-24871-5

Kumar, Y., V. Singh, G. Kumar, N. K. Gupta, \& A. K. Tahlan. 2019. Serovar diversity of Salmonella among poultry. Indian J. Med. Res. 150:92-95. https://doi.org/10.4103/ijmr. IJMR_1798_17

Medhat, D., H. A. El-mezayen, M. E. El-Naggar, A. Farrag, M. E. Abdelgawad, J. Hussein, \& M. H. Kamal. 2019. Evaluation of urinary 8-hydroxy-2-deoxyguanosine level in experimental Alzheimer's disease: Impact of carvacrol nanoparticles. Mol. Biol. Rep. 46:4517-4527. https://doi. org/10.1007/s11033-019-04907-3

Mshelbwala, F. M., N. D. Ibrahim, S. N. Saidu, A. A. Azeez, P. A. Akinduti, C. N. Kwanashie, A. K. F. Kadiri, M. Muhammed, I. O. Fagbamila, \& P. D. Luka. 2017. Motile Salmonella serotypes causing high mortality in poultry farms in three South-Western States of Nigeria. Vet. Rec. Open 4:e000247. https://doi.org/10.1136/ vetreco-2017-000247

Osman, K. M., A. M. M. Yousef, M. M. Aly, \& M. I. Radwan. 2010. Salmonella spp. infection in imported 1-day-old chicks, ducklings, and turkey poults: a public health risk. Foodborne pathog. Dis. 7:383-90. https://doi.org/10.1089/ fpd.2009.0358

Pathania, R., H. Khan, R. Kaushik, \& M. A. Khan. 2018. Essential oil nanoemulsions and their antimicrobial and food applications. Curr. Res. Nutr. Food Sci. 6:626-643. https://doi.org/10.12944/CRNFSJ.6.3.05

Pongsumpun, P., S. Iwamoto, \& U. Siripatrawan. 2019. Response surface methodology for optimization of cinnamon essential oil nanoemulsion with improved stability and antifungal activity. ULTRASON SONOCHEM. 60. https://doi.org/10.1016/j.ultsonch.2019.05.021

Quinn P. J., B. K. Markey, M. E. Carter, W. J. C. Donnelly, F. C. Leonard, \& D. Maguire. 2002. Veterinary Microbiology and Microbial Disease. Blackwell, New Jersey. p. 113-116.

Rattanachaikunsopon, P. \& P. Phumkhachorn. 2010. Antimicrobial Activity of Basil (Ocimum basilicum) Oil against Salmonella enteritidis in Vitro and in Food. Biosci. Biotechnol. Biochem. 74:1200-1204. https://doi.org/10.1271/ bbb. 90939

Ribeiro, S. O., V. Fontaine, V. Mathieu, A. Zhiri, D. Baudoux, C. Stevigny, \& F. Souard. 2020. Antibacterial and cytotoxic activities of ten commercially available essential oils. Antibiotics. 9:717. https://doi.org/10.3390/ antibiotics 9100717
Rusenova, N. \& P. Parvanov. 2009. Antimicrobial activities of twelve essential oils against microorganisms of veterinary importance. Trakia J. Sci. 7:37-43.

Sakkas, H. \& C. Papadopoulou. 2017. Antimicrobial activity of basil, oregano, and thyme essential oils. J. Microbiol. Biotechnol. 27:429-438. https://doi.org/10.4014/ jmb.1608.08024

Sedeik, M. E., N. A. El-shall, A. M. Awad, S. M. Elfeky, M. E. Abd El-Hack, E. O. S. Hussein, A. N. Alowaimer, \& A. A. Swelum. 2019. Isolation, conventional and molecular characterization of Salmonella spp. from newly hatched broiler chicks. AMB Expr. 9:136. https://doi.org/10.1186/ s13568-019-0821-6

Shekhar, C. 2018. Global impact of salmonellosis on health and economy. (Special Issue- 4) International Conference on Food Security and Sustainable Agriculture (Thailand on 21-24 December 2018). J. Pharmacogn. Phytochem. SP4:93-96.

Soković, M., J. Glamočlija, P. D. Marin, D. Brkić, \& L. J. L. D. van Griensven. 2010. Antibacterial effects of the essential oils of commonly consumed medicinal herbs using an in vitro model. Molecules 15:7532-7546. https://doi. org/10.3390/molecules15117532

Sotelo-Boy'as, M. E., G. Valverde-Aguilar, M. PlascenciaJatomea, Z. N. Correa-Pacheco, A. Jim'enez-Aparicio, J. Solorza-Feria, L. Barrera-Necha, \& S. Bautista-Ba nos. 2015. Characterization of chitosan nanoparticles added with essential oils. In vitro effect on Pectobacterium carotovorum. Rev. Mex. Ing. Quim. 14:589-599.

Van de Vel, E., I. Sampers, \& K. Raes. 2019. A review on influencing factors on the minimum inhibitory concentration of essential oils. Crit. Rev. Food Sci. Nutr. 59:357-378. https:// doi.org/10.1080/10408398.2017.1371112

Wibisono, F. M., F. J. Wibisono, M. H. Effendi, H. Plumeriastuti, A. R. Hidayatullah, E. B. Hartadi, \& E. D. Sofiana. 2020. A Review of salmonellosis on poultry farms: Public health importance. Sys. Rev. Pharm. 11:481-486.

Wu, Y., Y. Luo, \& Q. Wang. 2012. Antioxidant and antimicrobial properties of essential oils encapsulated in zein nanoparticles prepared by liquid-liquid dispersion method. LWTFood Sci. Technol. 48: 283-290. https://doi.org/10.1016/j. lwt.2012.03.027

Yang, J., Z. Ju, Y. Yang, X. Zhao, Z. Jiang, \& S. Sun. 2019. Serotype, antimicrobial susceptibility, and genotype profiles of Salmonella isolated from duck farms, and a slaughterhouse in Shandong province, China. BMC Microbiology 19:202. https://doi.org/10.1186/s12866-019-1570-z 